\title{
Welcome to the PNAE Congress 2016
}

Dear colleagues,

We are delighted to welcome you to the 3rd PNAE congress on Paediatric Nursing organised by the Paediatric Nursing Associations of Europe in collaboration with Escola Superior de Enfermagem do Porto (ESEP) and Ordem dos Enfermeiros (OE).

We have joined forces to promote the sharing of knowledge and experience with the aim of enhancing paediatric nursing care across Europe. The scientific programme will include distinguished keynote speakers from countries across Europe, as well as oral and poster presentations from paediatric and neonatal nurses who will share with us their research findings, service improvements, empirical knowledge and experiences regarding the care of infants, children, young people and their families.

We owe particular thanks to ESEP and to OE for their support in enabling this congress to be held at ESEP - Portugal.

We anticipate that paediatric nurses from across Europe will attend this congress to enrich their knowledge and to hear about the latest developments in the care of children, young people and their families. The congress will provide the opportunity to network, share ideas and learn from colleagues about improving the care and outcomes for infants, children and young people.

We look forward to welcoming you to the vibrant city of Porto and hope you have an enjoyable and fruitful stay.

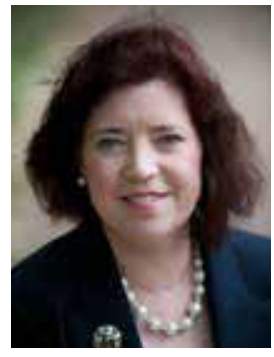

Fiona Smith Chair: Conference Organising Committee

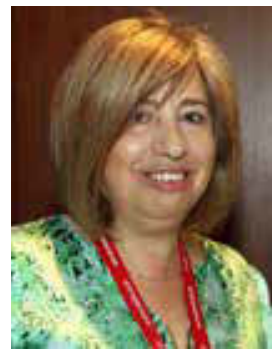

Maria do Céu Barbieri Chair: Conference Scientific Committee 